\title{
Cardiac Fibroblasts Contribute to Myocardial Dysfunction in Mice with Sepsis: The Role of NLRP3 Inflammasome Activation
}

\author{
Wenbo Zhang ${ }^{1,2}$, Xuemei $\mathrm{Xu}^{2,3}$, Raymond $\mathrm{Kao}^{2,3}$, Tina Mele ${ }^{2,3}$, Peter Kvietys ${ }^{4}$, Claudio M. Martin ${ }^{2,3}$, \\ Tao Rui ${ }^{1,2,3,5 *}$
}

1 Departments of Medicine and Surgery, the Affiliated People's Hospital of Jiangsu University, Zhenjiang, Jiangsu Province, China, 2 Critical IIIness Research, Lawson Health Research Institute, London, Ontario, Canada, 3 Critical Care Western, Department of Medicine, Schulich School of Medicine and Dentistry, University of Western Ontario, London, Ontario, Canada, 4 Department of Physiology \& Biochemistry, College of Medicine, Alfaisal University, Riyadh, Saudi Arabia, 5 Department of Pathology, Schulich School of Medicine and Dentistry, University of Western Ontario, London, Ontario, Canada

\begin{abstract}
Myocardial contractile dysfunction in sepsis is associated with the increased morbidity and mortality. Although the underlying mechanisms of the cardiac depression have not been fully elucidated, an exaggerated inflammatory response is believed to be responsible. Nucleotide-binding oligomerization domain-like receptor containing pyrin domain 3 (NLRP3) inflammasome is an intracellular platform that is involved in the maturation and release of interleukin (IL)-1 $\beta$. The aim of the present study is to evaluate whether sepsis activates NLRP3 inflammasome/caspase-1/IL-1 $\beta$ pathway in cardiac fibroblasts (CFs) and whether this cytokine can subsequently impact the function of cardiomyocytes (cardiac fibroblast-myocyte crosstalk). We show that treatment of CFs with lipopolysaccharide (LPS) induces upregulation of NLRP3, activation of caspase-1, as well as the maturation (activation) and release of IL-1 $\beta$. In addition, the genetic (small interfering ribonucleic acid [siRNA]) and pharmacological (glyburide) inhibition of the NLRP3 inflammasome in CFs can block this signaling pathway. Furthermore, the inhibition of the NLRP3 inflammasome in cardiac fibroblasts ameliorated the ability of LPS-chalenged CFs to impact cardiomyocyte function as assessed by intracellular cyclic adenosine monophosphate (cAMP) responses in cardiomyocytes. Salient features of this the NLP3 inflammasome/ caspase-1 pathway were confirmed in in vivo models of endotoxemia/sepsis. We found that inhibition of the NLRP3 inflammasome attenuated myocardial dysfunction in mice with LPS and increased the survival rate in mice with feces-induced peritonitis. Our results indicate that the activation of the NLRP3 inflammasome in cardiac fibroblasts is pivotal in the induction of myocardial dysfunction in sepsis.
\end{abstract}

Citation: Zhang W, Xu X, Kao R, Mele T, Kvietys P, et al. (2014) Cardiac Fibroblasts Contribute to Myocardial Dysfunction in Mice with Sepsis: The Role of NLRP3 Inflammasome Activation. PLoS ONE 9(9): e107639. doi:10.1371/journal.pone.0107639

Editor: Hongwei Gao, Harvard Medical School, United States of America

Received April 7, 2014; Accepted August 11, 2014; Published September 12, 2014

Copyright: (C) 2014 Zhang et al. This is an open-access article distributed under the terms of the Creative Commons Attribution License, which permits unrestricted use, distribution, and reproduction in any medium, provided the original author and source are credited.

Data Availability: The authors confirm that all data underlying the findings are fully available without restriction. All relevant data are within the paper.

Funding: This work was supported by a Grant in Aid from the Heart and Stroke Foundation of Ontario (GIA 2012-000212 to TR) and a Internal Research Fund from Lawson Health Research Institute (To TR). The funders had no role in study design, data collection and analysis, decision to publish, or preparation of the manuscript.

Competing Interests: The authors have declared that no competing interests exist.

* Email: trui@uwo.ca

\section{Introduction}

Sepsis and septic shock are common entities encountered in intensive care units and they are associated with high mortality rates [4,39]. Mortality in septic patients is primarily due to multiple organ failure (MOF) rather than from the initial infection [1]. The heart is one of the organs affected in MOF and myocardial dysfunction is associated with poor outcomes [23]. Myocardial dysfunction in septic patients has been attributed to an exaggerated inflammatory response [23]. As the most important functional cells within the heart, most experimental studies addressing the mechanisms of sepsis-induced myocardial dysfunction have focused on the cardiomyocyte. For example, proinflammatory cytokines released by cardiomyocytes during sepsis play an important role in the induction of decreased myocardial contractility [21]. While the cardiomyocytes make up $<50 \%$ of the total cell population of the heart, cardiac fibroblasts $(\mathrm{CFs})$ account for up to $60 \%,[13,46]$. Importantly, the two cell types are spatially intermingled in the myocardium, with virtually every cardiomyocytes bordering one or more CFs. This spatial arrangement allows for cardiac fibroblast-myocyte communication or "cross-talk". The cross-talk between the CFs and cardiomyocytes can be mediated by paracrine signalling, direct cell-cell contact via micro tubules, and through indirect interactions via the extracellular matrix [46]. These interactions are not only important in normal cardiac functioning, but they also play roles in myocardial pathologies $[13,31,46]$.

Interleukin (IL)-1 $\beta$ is a powerful cytokine that has been reported to be involved in sepsis-induced myocardial dysfunction [5]. Proinflammatory stimuli induce the expression of pro-IL-1 $\beta$, which is an inactivated form of the cytokine. The maturation and release of the active form of IL- $1 \beta$ are controlled by inflammasomes, which are intracellular multi-protein platforms [17]. Activation of the inflammasomes (by PAMPs or DAMPS) triggers 
the maturation (activation) and secretion of IL-1 $\beta$, therefore engaging in the inflammatory response $[17,25]$.

The nucleotide-binding oligomerization domain-like receptor containing pyrin domain 3 (NLRP3) inflammasome is one of the most well characterized inflammasomes [25,36]. It consists of the NLRP3 scaffold, which is a nucleotide-binding oligomerization domain-like receptor with a pyrin domain 3, the ASG (PYCARD) adaptor, and procaspase-1 [17]. The NLRP3 is an exceptional sensor protein that responds to diverse physical and chemical stimuli, as well as to cell stress signals, such as reactive oxygen species (ROS), extracellular adenosine triphosphate (ATP) $[9,22]$. As a common substrate of various inflammasomes, pro-caspase-1 is converted to its active form, caspase- 1 (consisting of p20 and p10 heterotetramers). Caspase-1 cleaves intracellular pro-IL-1 $\beta$ to yield the mature, active IL-1 $\beta$ (p17), which is secreted into the extracellular space [34].

The NLRP3 inflammasome is predominantly expressed in CFs, while the levels of the NLRP3 inflammasome in the cardiomyocytes are limited [27]. Inappropriate activation of the NLRP3 inflammasome in CFs has been implicated in ischemia/reperfusion-induced myocardial injury [27]. In the present study, we provide evidence indicating that the NLRP3 inflammasome in CFs is activated in sepsis and increases IL- $1 \beta$ production. The GFderived IL-1 $\beta$ impacts on cardiomyocyte (cardiac fibroblastmyocyte cross-talk) and impairs its contractile function.

\section{Materials and Methods}

\section{Mice}

C57BL/6 mice were obtained from Charles River Canada (St. Constant, QC, Canada) and were housed in the Vivarium Service of Victoria Research Laboratories with a 12-hr light/dark cycle and free access to rodent chow and tap water. The mice were used for in vivo experiments, and they served as a source for the isolation of CFs. Mouse breeding pairs were used to generate neonatal mice for the isolation of cardiomyocytes for the in vitro experiments. The experimental protocols were approved by the Western University Animal Care and Use Committee (protocol\# 2006-111).

\section{Preparation of CFs and cardiomyocytes}

CFs were derived from adult mice, as previously reported, with minor modifications [24,30,35]. In brief, heart tissue was dissected enzymatically (Collagenase II, $160 \mathrm{U} / \mathrm{ml}$ ). After performing washing steps, the cell suspension was passed through a nylon filter $(70 \mu \mathrm{m})$, and endothelial cells were removed with a magnetic beads technique [26]. Cells were subsequently placed in a humidified incubator gassed with $5 \% \mathrm{CO} 2$ at $37^{\circ} \mathrm{C}$ for $1 \mathrm{hr}$. The adherent cells were mainly CFs, and the non-adherent cells (cardiomyocytes) were removed. Finally, the CFs were cultured with Dulbecco's Modified Eagle's Medium (DMEM)-F12 supplemented with $10 \%$ fetal calf serum (FCS), $20 \mathrm{mM} \mathrm{L}$-glutamine and $100 \mathrm{U} / \mathrm{ml}$ penicillin $\mathrm{G}$, and $100 \mu \mathrm{g} / \mathrm{ml}$ streptomycin. This method yielded a $95 \%$ purity of $\mathrm{CF}$, as identified by the positive staining of a fibroblast marker (ER-TR7) [32]. Cells of one through three passages were used for the experiments.

Neonatal cardiomyocytes were isolated and cultured, as previous described [44]. Briefly, hearts were harvested, minced, and digested with Collagenase II. After a washing step, the cells were suspended in M199 with 10\% FCS. The myocytes were enriched by a pre-plating approach (to remove contaminating cells) before being seeded into cell culture plates. After $72 \mathrm{hrs}$ in culture, the cells had formed a confluent monolayer consisting of $95 \%$ myocytes beating in synchrony, and they were used in the experiments at this time.

\section{Endotoxemia/sepsis models}

To study the role of NLRP3 inflammasome in myocardial inflammation and myocardial dysfunction, a mouse model of endotoxemia was induced by the intraperitoneal (i.p.) injection of $0.5 \mathrm{ml}$ of normal saline containing lipopolysaccharides (LPS, $10 \mathrm{mg} / \mathrm{kg}$ ) to 3-month-old mice, as previously described [41]. As an in vitro correlate of the mouse model of endotoxemia, CFs were exposed to DMEM F12 with LPS (LPS, $1 \mu \mathrm{g} / \mathrm{ml}$ ). In addition, a multimicrobial sepsis model was established using feces-induced peritonitis (FIP) approach. The FIP was induced by an injection (i.p.) of $0.5 \mathrm{ml}$ of pooled fecal material $(30 \mathrm{mg} / \mathrm{ml}$ in normal saline) to 3-month-old mice [43]. As this was a more severe model, pain control was managed with subcutaneous injection of buprenorphine $(50 \mu \mathrm{g} / \mathrm{Kg}$, every $12 \mathrm{hrs})$.

NLRP3 inflammasome blockade. Both pharmacologic and genetic blockade approaches were used to assess the role of NLRP3 inflammasome in the endotoxemia/sepsis models. Glyburide is a sulfonylurea drug used for the treatment of type 2 diabetes. It inhibits adenosine triphosphate (ATP)-sensitive $\mathrm{K}^{+}$ channels, and it is the first identified compound to inhibit the NLRP3 inflammasome [16]. In addition, NLRP3 silencing approach was employed using small interfering RNA (siRNA).

\section{Experimental protocols}

Mice (16 mice per group) were randomly allocated to the following 4 groups: sham, LPS, LPS with glyburide as well as glyburide only. Glyburide (Invivogen, San Diego, CA, USA) was given $(1 \mathrm{mg} / \mathrm{Kg}$, i.p.) $30 \mathrm{~min}$ before the LPS challenge. Equivalent volume ( $2 \mu$ l, i.p.) of vehicle (dimethyl sulfoxide, DMSO) was administered to sham and LPS group. The mice were sacrificed 8 hours after LPS injection, and plasma as well as myocardial tissue was harvested for assay. Alternatively, the mice were subjected to myocardial function evaluation 24 hours after LPS injection. FIP mice were used to assess whether inhibition of NLRP3 inflammasome could afford a survival benefit. The FIP mice were randomly divided into two groups (10 mice/group), which were injected i.p. daily with either glyburide $(1 \mathrm{mg} / \mathrm{Kg}$.) or the equal volume of DMSO in $300 \mu \mathrm{l} \mathrm{PBS}$, with the first dosing being 30 min prior to FIP. The mice were monitored hourly up to $72 \mathrm{hrs}$ for the following 5 parameters: general appearance (abnormal posture, lethargy, depressed appetite, hypothermia, swelling, ruffled fur, piloerection), dehydration, weight loss, labored respiration, behaviour and activity (interest in surroundings, gettingt up without prompting, normal gait, steady on feet, ability to access food and water). Each parameter scored from 0 (normal) to 4 (very abnormal). Mice with a score of 10 were monitored more frequently to identify deteriorating conditions. Mice with a score of 20 were considered to be moribund and were humanely euthanized with cervical dislocation.

As an in vitro model of endotoxemia, CFs were challenged with LPS; saline (vehicle) was added to the media as a control. To identify the optimal time window for activation of NLRP3 inflammasome, the cells were treated with LPS for 4, 8, 12 and $24 \mathrm{hrs}$. Based on the results, a 24-hour period of LPS challenge was used in the following experiments. To study the role of NLRP3 inflammasome in LPS-induced IL-1 $\beta$ production, glyburide $(50-200 \mu \mathrm{M})$ or equal volume of DMSO was added to the CFs $30 \mathrm{~min}$ prior to LPS treatment.

\section{Western blot}

Protein levels of NLRP3, pro-caspase-1, caspase-1 p10 (activated caspase), pro-IL-1 $\beta$, and mature IL- $1 \beta$ were assessed in either tissue or cells using Western blot [41]. Briefly, CFs were lysed or mouse myocardial tissue were homogenized in lysis buffer $(10 \mathrm{mM}$ 
Tris [pH 7.4], $150 \mathrm{mM} \mathrm{NaCl,} 5 \mathrm{mM}$ EDTA, $1 \%$ Triton X-100, $10 \mathrm{mM}$ NaF, $1 \mathrm{mM}$ Na3VO4, $10 \mu \mathrm{g} / \mathrm{ml}$ leupeptin, $10 \mu \mathrm{g} / \mathrm{ml}$ aprotinin, and $20 \mathrm{mM} \mathrm{PMSF}$ ). The supernatants were processed using the BCA method, and 10-50 $\mathrm{g}$ total protein for each sample was separated on 10-15\% sodium dodecyl sulfate (SDS)polyacrylamide gels (PAGE) and transferred to polyvinilide fluoride (PVDF) membranes. After blocking with 3\% bovine serum albumin (Wisent Inc, St-Bruno, QC, Canada), the membranes were probed with primary antibodies against mouse NLRP3 (Adipogen, San Diego, CA, USA) at 1:500 dilution, procaspase-1, caspase-1 p10 (Santa Cruz, Dallas, TX, USA) at 1:200, or pro-IL-1 $\beta$, IL-1 $\beta$ (R and D Systems, Minneapolis, MN, USA) at 1:500, or tubulin (abcam, Toronto, ON, Canada) at 1:2000. After being incubated with relevant secondary antibodies, the specific bands were visualized with an enhanced chemiluminescence (ECL) detection system, and quantified with an Imaging Densitometer (Bio-Rad Laboratories, Inc., Hercules, CA, USA).

\section{ELISA}

IL-1 $\beta$ in culture supernatants, mouse plasma or myocardial homogenates was detected with a BD OptEIA mouse IL-1 $\beta$ ELISA kit (BD Biosciences, San Diego, CA, USA) according to the manufacturer's instructions. Culture medium was centrifuged at $500 \mathrm{~g}$ for $5 \mathrm{~min}$, and the supernatant was collected and stored at $80^{\circ} \mathrm{C}$ until assay. Blood samples from left common carotid artery were collected and plasma was obtained by centrifugation at 4,000 g for $10 \mathrm{~min}$. Myocardial tissue from the left ventricle was homogenized in PBS containing a protease inhibitor cocktail. The homogenates were centrifuged at $10,000 \mathrm{~g}$ for $30 \mathrm{~min}$ to remove debris and insoluble material, and aliquots of the supernatants were ready for IL- $1 \beta$ measurements. The data are expressed at $\mathrm{pg} / \mathrm{mg}$ protein, with protein concentration determined using the BCA method.

\section{NLRP3 siRNA}

For the small interfering RNA (siRNA) assay, GFs were transiently transfected with $40 \mathrm{nM}$ scrambled siRNA or NLRP3 siRNA (Life Technologies, Burlington, ON, Canada) using Lipofectamine 2000 (Life Technologies, Burlington, ON, Canada) according to the manufacturer's instructions [43]. Successful down-regulation of LPS-induced NLRP3 expression in CFs in all experiments was confirmed by Western blot analysis. $48 \mathrm{hrs}$ after the procedure, the CFs with siRNA were used in the experiments involving the role of NLRP3 inflammasome in LPS-induced IL-1 $\beta$ production and the role of NLRP3 inflammasome in mediating CFs-cardiomyocytes interaction.

\section{Intracellular cyclic adenosine monophosphate (cAMP)}

An increase in intracellular cAMP in cardiomyocytes/myocardial tissue in response to $\beta$-adrenergic agonist stimulation is generally associated with enhanced myocardial contractility and an impaired cAMP response to $\beta$-adrenergic agents has been reported in both in vitro and in vivo septic models [28,29]. Thus, the role of NLRP3 in modulating the cAMP response to the $\beta$ adrenergic agonist, dobutamine in isolated cardiomyocytes was assessed. Firstly, CFs were pre-transfected with NLRP3 siRNA, or pre-treated with glyburide $(200 \mu \mathrm{M})$, followed by a LPS challenge for $24 \mathrm{hrs}$. The various supernatants derived from LPS- or vehicleconditioned $\mathrm{CFs}$ were harvested and transferred to naïve cardiomyocytes and incubated for an additional $24 \mathrm{hrs}$. The potential role of IL-1 $\beta$ on cAMP accumulation was studied by adding IL-1 $\beta$ ( $5 \mathrm{ng} / \mathrm{mL}$ ) (Millipore, Billerica, MA, USA) to naïve cardiomyocytes as indicated. To block the effect of IL-1 $\beta$, IL-1 receptor antagonist (IL-1Ra, $5 \mu \mathrm{g} / \mathrm{ml}$ ) (Millipore, Billerica, MA,
USA) was simultaneously added to the cardiomyocytes as needed. At $24 \mathrm{hrs}$ post treatment, the cardiomyocytes were washed once and incubated for $15 \mathrm{~min}$ in physiological buffer at $37^{\circ} \mathrm{C}$. Subsequently, the myocytes were treated with $7.5 \mu \mathrm{M}$ dobutamine (Sigma-Aldrich, St. Louis, MO, USA) or vehicle for 10 minutes; after which the buffer was aspirated and replaced with $0.1 \mathrm{M} \mathrm{HCl}$. The cell lysates were used to detect the intracellular cAMP with a cAMP direct immunoassay kit (BioVision, Milpitas, CA, USA) as per the manufacturer's instructions.

\section{Myocardial contractile function}

$24 \mathrm{hrs}$ after the injection of LPS or saline, mice were anesthetized with ketamine $(150 \mathrm{mg} / \mathrm{kg})$ and xylazine $(5 \mathrm{mg} / \mathrm{kg})$, which were administered subcutaneously. A Millar tip transducer catheter (Model SPR-839, 1.4 Fr.) was advanced into the left ventricle (LV) via the right carotid artery. Pressure-volume (PV) measurements were taken during quiet respiration and recorded using a Millar PV Conductance Unit (Model MPCU-200) and Power Lab Data Acquisition System (ADInstruments). The raw pressure and volume data collected in text files by the MPGU-200 unit and Chart/ Powerlab software were imported into the PVAN software (Millar Instruments, Houston, TX). LV pressure--volume loops were generated by occlusion of the inferior caval vein $[11,41]$. The LV end-systolic pressure-volume relation (ESPVR) was calculated and used as an index of myocardial contractile function [41,42].

\section{Statistical analysis}

All data are expressed as the mean \pm standard error of the mean. Statistical analysis was performed using analysis of variance and Student's $t$-test (with a Bonferroni correction for multiple comparisons), as well as with the Kaplan-Meier test.

\section{Results}

Challenging CFs with LPS activates NLRP3 inflammasome and results in caspase-1 activation and increased IL-1 $\beta$ maturation and release

The NLRP3 inflammasome is a molecular platform that is activated upon cellular infection or stress and triggers the maturation (activation) and secretion of IL-1 $\beta$, to engage the inflammatory response [17]. In order to determine whether LPS treatment activates the NLRP3 inflammasome and subsequent processing and secretion of IL- $1 \beta$ in CFs, we measured the intracellular levels of NLRP3, pro-caspase-1, caspase-1 p10, proIL-1 $\beta$, as well as the intracellular and released IL-1 $\beta$. As shown in Figure 1, levels of intracellular NLRP3, pro-caspase-1, and proIL-1 $\beta$ following the LPS treatment of CFs were increased (Figures 1A, 1B and 1D). Moreover, LPS treatment resulted in caspase-1 activation, as indicated by increased intracellular caspase-1 p10 (Figure 1G) and IL-1 $\beta$ maturation and release into the extracellular milieu (Figures 1E and 1F). These results are consistent with the NLRP3 inflammasome/caspase-1 pathway being operative in LPS-challenged cardiac fibroblasts.

To investigate the role of the NLRP3 inflammasome in LPSinduced IL-1 $\beta$ production by the CFs, the cells were transfected with siRNA, which was specific for NLRP3, or CFs were pretreated with glyburide (an inhibitor of NLRP3 inflammasomes) prior to the LPS challenge [16]. Transfection of the CFs with siRNA specific to NLPR 3 blocked the LPS-induced increase in intracellular NLRP3 expression by approximately $70 \%$ (Figure 2A). Moreover, the NLPR 3 siRNA prevented the LPS-induced activation of caspase-1 (Figure 2B), as well as the maturation and release of IL-1 $\beta$ Figures 2G and 2D). Further, pretreatment of the CFs with glyburide had no effect on LPS-induced increases in the intracel- 
A

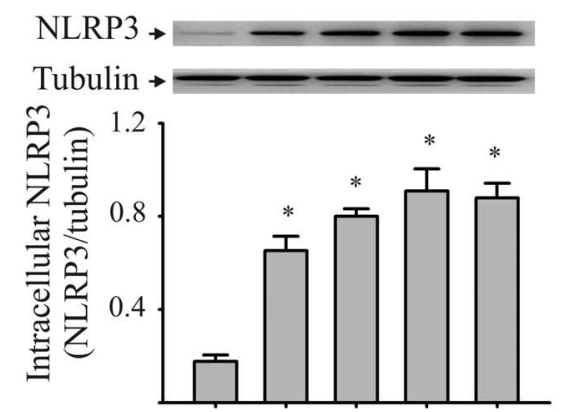

B
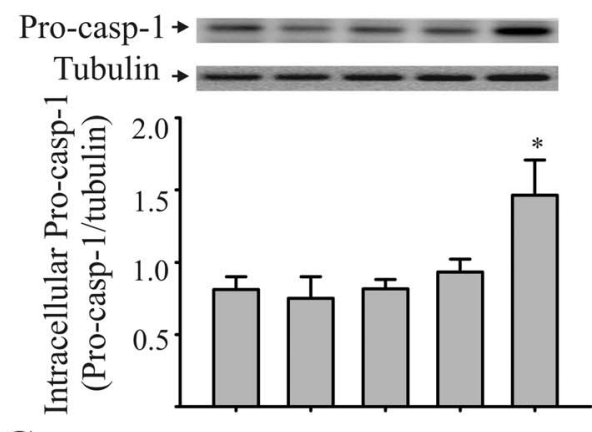

$\mathrm{C}$

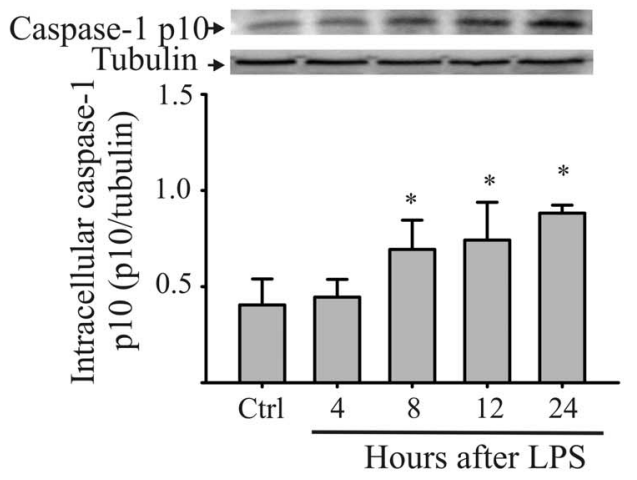

$\mathrm{D}$

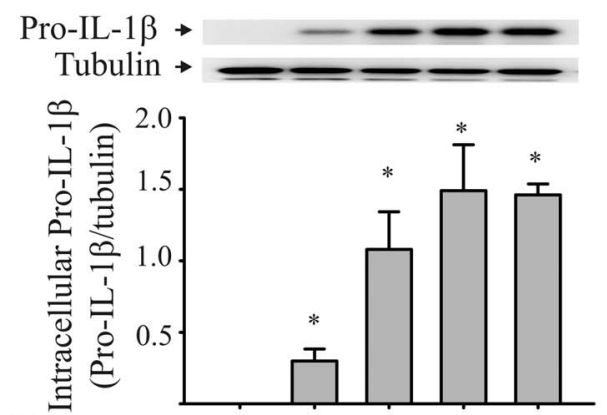

$\mathrm{E}$

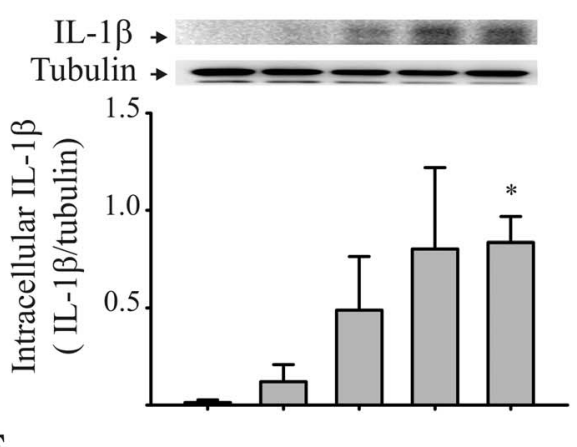

$\mathrm{F}$

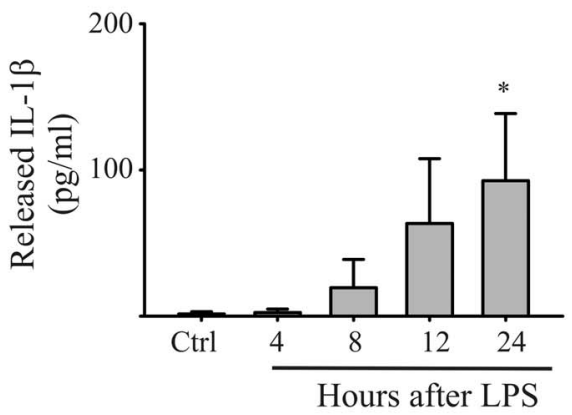

Figure 1. Treatment of cardiac fibroblasts (CFs) with LPS activates the NLRP3 inflammasome and results in the maturation (activation) and release of IL-1ß. Mouse CFs were challenged with LPS $(1 \mu \mathrm{g} / \mathrm{ml})$ or saline (control). At the times indicated, the CFs were collected, lysed, and processed for the measurement (Western blot) of intracellular NLRP3 (A), pro-caspase-1 (B), activated caspase-1 p10 (C), pro-IL-1 $\beta$ (D), and IL-1 $\beta$ (E). Released IL-1 $\beta$ was also assessed by ELISA of the supernatants (F). For A through E, representative blots and densitometric analyses are shown. $n=3$ for all experiments $(A-F),{ }^{*} p<0.05$, compared with control. doi:10.1371/journal.pone.0107639.g001

lular expression of NLRP3, pro-caspase-1 and pro-IL-1 $\beta$ (Figures 3A, 3B and 3D). However, glyburide prevented LPS-induced caspase-1 activation (Figure 3C), and it attenuated the LPSinduced IL-1 $\beta$ maturation and release by the CFs (Figures 3E and $3 \mathbf{F}$ ) in a dose-dependent manner.

\section{Activation of NLRP3 inflammasome in CFs by LPS negatively regulates intracellular CAMP response to dobutamine in cardiomyocytes}

Since the contractile activity of cardiomyocytes in our culture system was not amenable to quantitation, an indirect index of myocyte contractile function was assessed, i.e., intracellular cAMP. cAMP elevation, particularly through $\beta$-adrenergic receptor $(\beta$ AR) stimulation, has crucial positive cardiac inotropic effect. Further, the NLRP3 inflammasome is predominantly expressed in CFs, while the levels of the NLRP3 inflammasome in the cardiomyocytes are limited [27]. To determine the role of NLRP3 inflammasome activation in CFs on the function of cardiomyocytes, the cardiomyocytes were challenged with the supernatants of $\mathrm{CF}$ s that were conditioned with different challenges. Subsequently, the intracellular levels of the cAMP of cardiomyocytes in response to dobutamine were assessed. As shown in Figure 4A, cAMP levels in cardiomyocytes more than doubled after challenge with dobutamine compared with control. Supernatants of the CFs preconditioned with LPS blunted the dobutamine-induced elevation of intracellular cAMP by $80 \%$ (Figure $4 \mathbf{A}$ ). This inhibitory effect was partially reversed $(\approx 60 \%$ reversal) by the pretreatment of the LPS-conditioned CFs with either NLRP3 siRNA or glyburide (Figure 4A). These data indicate that the activation of the NLRP3 inflammasome in CFs negatively affects the cardiomyocyte cAMP response to dobutamine. 
A

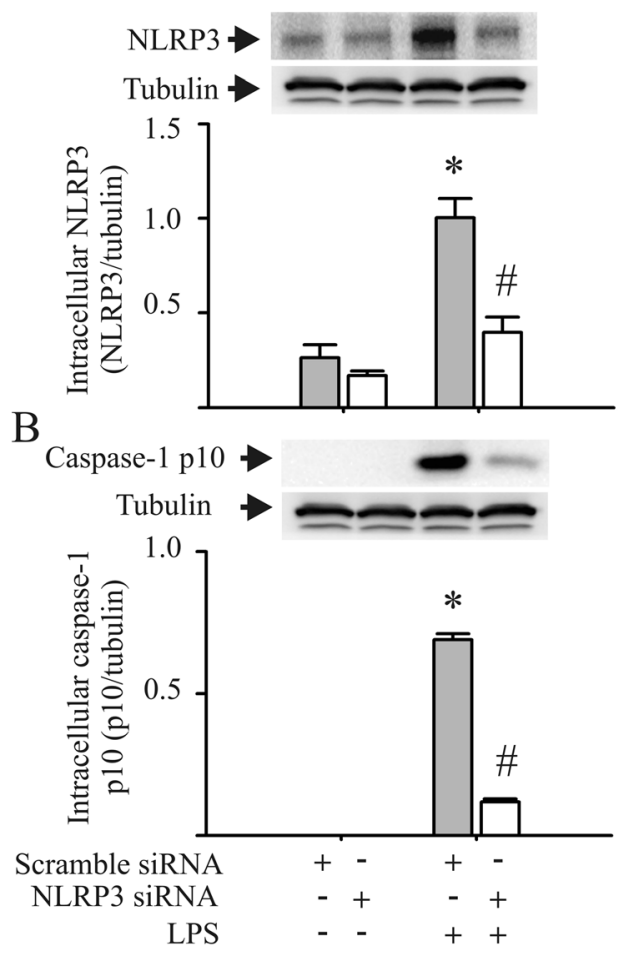

$\mathrm{C}$

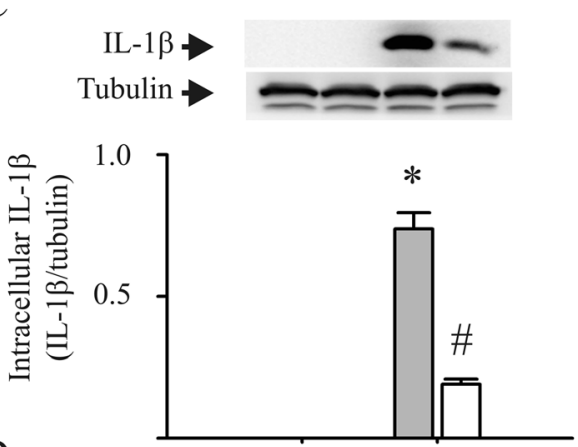

D

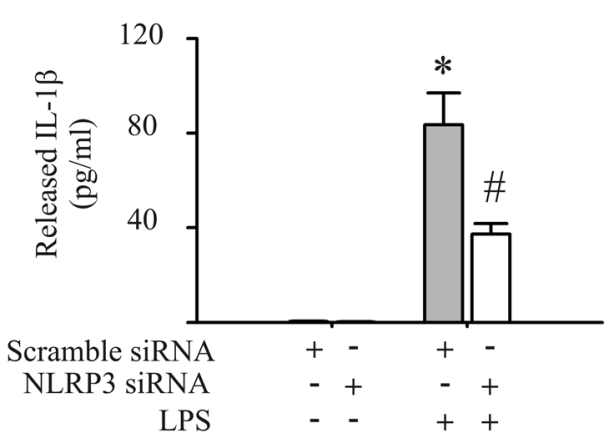

Figure 2. siRNA knock down of NLRP3 prevents LPS-induced caspase-1 activation and IL-1 $\beta$ production by cardiac fibroblasts (CFs). CFs were transfected with siRNA specific to NLRP3 or with scrambled siRNA. Forty eight hrs after transfection, the cells were challenged with LPS $(1 \mu \mathrm{g} / \mathrm{ml})$ or vehicle for $24 \mathrm{hrs}$. The cells were lysed for the detection of intracellular NLRP3 (A), caspase-1 p10 (B), and intracellular IL-1 $\beta$ (C) with Western blot. The supernatants were harvested for the detection of released IL-1 $\beta$ with ELISA (D). For A, B, and C, representative blots and densitometric analyses are shown. $\mathrm{n}=3$ for all experiments (A-D). ${ }^{*} \mathrm{p}<0.05$ compared with control (no LPS challenge); \#p<0.05 compared with the scrambled siRNA in the LPS-challenged CFs.

doi:10.1371/journal.pone.0107639.g002

In another series of experiments, either IL-1 Ra $(5 \mu \mathrm{g} / \mathrm{ml})$ was introduced to the supernatant of LPS-conditioned CFs, or IL- $1 \beta$ $(5 \mathrm{ng} / \mathrm{ml})$ was directly added to the culture medium of cardiomyocytes. As shown in Figure 4B, the negative impact of the supernatants from the LPS-conditioned CFs on the cardiomyocytes response to dobutamine was partially reversed by IL-1Ra $(\approx 55 \%$ reversal). Moreover, IL-1 $\beta$ prevented the dobutamineinduced increase in intracellular cAMP in cardiomyocytes. The inhibitory effect of the IL- $1 \beta$ was also partially reversed by IL-1Ra $(\approx 55 \%$ reversal) (Figure $\mathbf{4 C}$ ). The results suggest that the NLRP3 inflammasome/IL-1 $\beta$ axis mediates the $\mathrm{CF}$-cardiomyocyte interaction, and can inhibit the increase in cAMP induced by dobutamine.

\section{Activation of the NLRP3 inflammasome contributes to} myocardial contractile dysfunction in endotoxemic mice

To determine whether studies using isolated CFs and cardiomyocytes could be translated to an in vivo setting, mice were either challenged with LPS $(10 \mathrm{mg} / \mathrm{kg})$ or LPS with glyburide $(1 \mathrm{mg} / \mathrm{kg})$. Mice challenged with vehicle served as the control. Myocardial NLRP3 inflammasome activation, myocardial and circulating IL-1 $\beta$, and cardiac function were assessed. As shown in Figure 5, the levels of myocardial NLRP3 increased $8 \mathrm{hrs}$ post LPS challenge in mice. Although pro-caspase-1 levels were unaltered, caspase-1 p10 levels were increased indicating that the NLRP3 inflammasome was activated. Further, LPS increased myocardial levels of activated IL-1 $\beta$ as well as circulating IL-1 $\beta$. Glyburide prevented 1) the LPS-induced activation of the myocardial capsase- 1 and IL- $1 \beta$, indicating a reduction in NLRP3 inflammasome activity, as well as 2) the increase in myocardial and circulating IL-1 $\beta$. Moreover, myocardial contractility was decreased in endotexemic mice (LPS-challenged), as indicated by the decrease in $\mathrm{LV} \pm \mathrm{dP} / \mathrm{dt}$, stroke work and ESPVR (Figure 6). Glyburide treatment attenuated the development of myocardial dysfunction in mice with LPS (Figure 6).

To assess whether the NLRP3 inflammasome/caspase-1 pathway would be activated in a polymicrobial model of sepsis we used the FIP model. In line with the LPS-induced endotoxemia model, the levels of myocardial NLRP3 and pro-IL-1 $\beta$ were also increased $8 \mathrm{hrs}$ post-FIP induction (Figure 7). Activation of NLRP3 inflammasome was evidenced by the increased myocardial levels of caspase- 1 p 10 and IL- $1 \beta$ as well as circulating IL- $1 \beta$. Glyburide prevented the FIP-induced activation of the myocardial NLRP3 inflammasome as well as FIP-induced increase in myocardial and circulating IL-1 $\beta$ (Figure 7).

Previous studies have demonstrated that NLRP3 ${ }^{-/-}$mice are resistant to LPS-induced lethality [20]. In accord with the role of NLRP3 inflammasome in endotoxemia, glyburide significantly delays LPS-induced lethality in mice [16]. In order to determine whether the inhibition of the NLRP3 inflammasome has beneficial effects on a multimicrobial (peritonitis) mouse model of sepsis, we used the FIP model. As shown in Figure 8, all FIP mice in vehicle-treated group died within $48 \mathrm{hrs}$ after induction of FIP, while FIP mice treated with glyburide daily showed a significant increase in survival rate. 
A

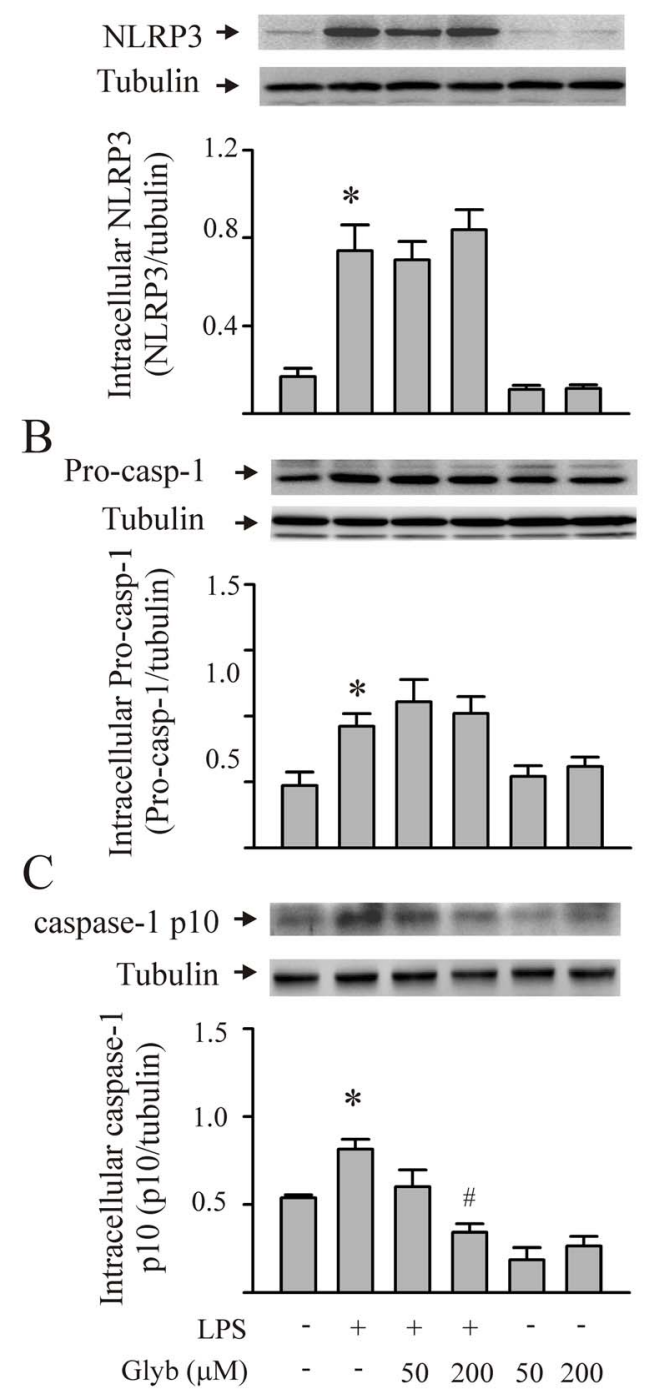

$\mathrm{D}$
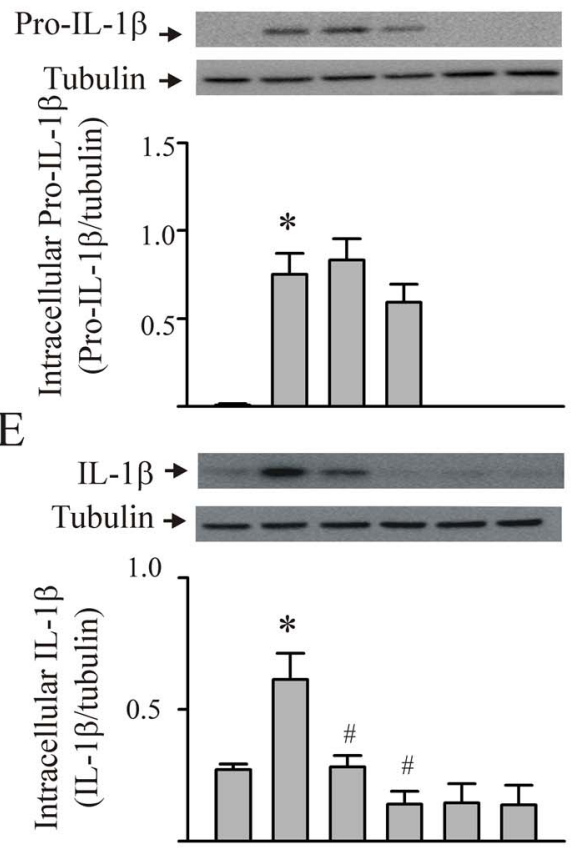

$\mathrm{F}$

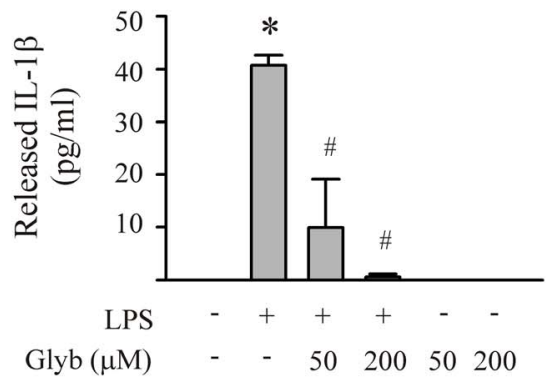

Figure 3. Inhibition of the NLRP3 inflammasome with glyburide (Glyb) prevents caspase-1 activation and IL-1 $\beta$ production by LPSchallenged cardiac fibroblasts (CFs). CFs were pretreated with either vehicle or glyburide (50 $\mu \mathrm{M}$ or $200 \mu \mathrm{M}) 30 \mathrm{~min}$ before the LPS (1 $\mu \mathrm{g} / \mathrm{ml})$ challenge. Twenty-four hrs after LPS stimulation, the cells were harvested and processed for the measurement (Western blot) of intracellular NLRP3 (A), pro-caspase-1 (B), activated caspase-1 p10 (C), pro-IL-1 $\beta(D)$, and mature IL-1 $\beta(E)$. The supernatants were harvested for the detection of released IL-1 $\beta$ with ELISA (F). The basal levels of the various components of the NLRP3 inflammasome/IL-1 $\beta$ axis were not affected by glyburide. For A through $E$, representative blots and densitometric analyses are shown. $n=3$ for all experiments (A-F). ${ }^{*} p<0.05$ compared with controls; \#p<0.05 compared with LPS treatment alone.

doi:10.1371/journal.pone.0107639.g003

\section{Discussion}

Myocardial dysfunction frequently accompanies severe sepsis and septic shock. It is now clear that cardiac dysfunction, as evidenced by biventricular dilatation and reduced ejection fraction, is present in most patients with severe sepsis [23]. Myocardial dysfunction does not appear to be due to myocardial hypoperfusion, but rather to an exaggerated inflammatory response [23]. However, the mechanisms and signaling pathways involved in eliciting the sepsis-induced inflammatory response remain elusive. An increasing body of evidence indicates that the NLPR3 inflammasome/caspase-1/IL-1 $\beta$ pathway may be involved. For instance, IL-1 $\beta$ is increased in both human and animal models of sepsis and septic shock [10] and an IL-1 antagonist attenuates the hemodynamic and metabolic manifestations of septic shock [6,7]. Further, genetic deletion or pharmacological inhibition of caspase-1 protects against endotoxemic shock in rodents [2,18]. Finally, mice deficient in components of the inflammasome complex (ASG or NLPR3) are more resistant to the lethal effects of endotoxin [19,20]. Although these isolated observations support a potential role for the NLRP3 inflammasome/caspase-1/IL-1 $\beta$ pathway, the present study is the first to provide a systematic assessment of this pathway in endotoxemia/ sepsis both in vivo and in vitro. Further, we show that blockade of the NLRP3 inflammasome/caspase-1/IL-1 $\beta$ pathway can afford protection against lethality in a model of polymicrobial sepsis. Finally, we provide evidence for cardiac fibroblast-myocyte crosstalk in the development of the sepsis-induced inflammatory response. 
A

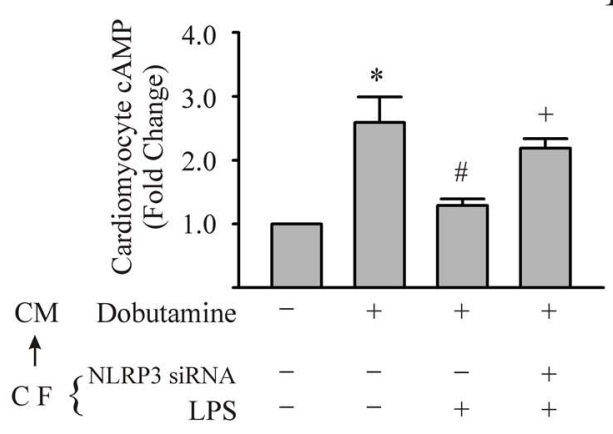

B

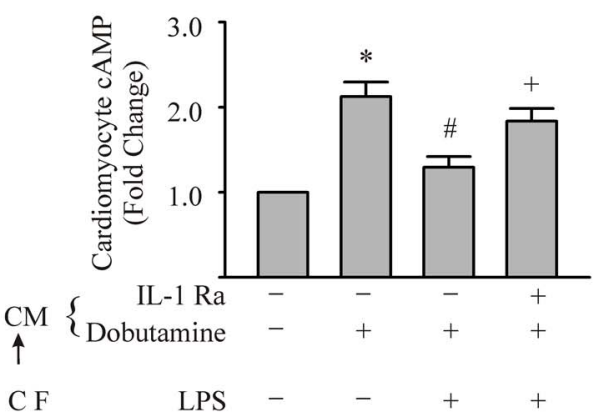

$\mathrm{C}$

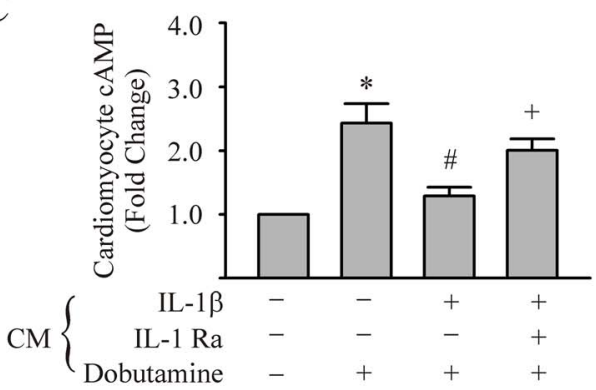

Figure 4. Supernatants from LPS-challenged cardiac fibroblasts (CFs) can inhibit the increase in cardiomyocyte (CM) CAMP induced by dobutamine; an effect dependent on an intact NLRP3 inflammasome/IL-1 $\beta$ axis in CFs. In panels A-C, CM were challenged with supernatants from LPS- or vehicle- conditioned $\mathrm{CFs}$. $(\mathrm{CF} \rightarrow \mathrm{CM})$. In Panel $\mathrm{A}$, the $\mathrm{CFs}$ were transfected with NLRP3 siRNA or glyburide $(200 \mu \mathrm{M})$ prior to challenge with LPS for $24 \mathrm{hrs}$. Subsequently, the supernatants were added to CM monolayers and thereafter, the cardiomyocytes were stimulated with vehicle or dobutamine $(7.5 \mu \mathrm{M})$ for $10 \mathrm{~min}$. The CM were harvested for the measurement of intracellular cAMP. In Panel B, CM were challenged with supernatants from LPS- or vehicle- conditioned CFs, with or without IL-1Ra $(5 \mu \mathrm{g} / \mathrm{ml})$ and intracellular cAMP assessed after dobutamine treatment. In panel C, CM were challenged with IL-1 $\beta(5 \mathrm{ng} / \mathrm{mL}$ ) or IL-1 $\beta$ plus IL-1Ra (5 $\mu \mathrm{g} / \mathrm{mL})$ for 24 hrs. Subsequently, the CM were challenged with dobutamine and cAMP of CM was assessed. For all experiments, $\mathrm{n}=3$ and *, $\#,+\mathrm{p}<0.05$ compared with previous bar in the histogram. doi:10.1371/journal.pone.0107639.g004

Both IL-1 $\beta$ and TNF- $\alpha$ appear to play important roles in endoxemia/sepsis-induced myocardial dysfunction. A concentration-dependent depression of contractility induced by IL-1 $\beta$ or TNF- $\alpha$ has been reported in in vitro or ex vivo studies in human and animal myocardial tissue $[3,8,15,37]$. The focus of the present study was on the NLRP3 inflammasome/caspase-1/IL-1 $\beta$ pathway. Of relevance, immunoabsorption of IL-1 $\beta$ can ameliorate cardiomyocyte depressant activity of human septic serum [15]. The cellular sources of IL- $1 \beta$ within the heart remain unclear at present. Inflammatory cells (e.g. macrophages, neutrophils) are well-documented sources of IL- $1 \beta$ production [45,47]. In addition to these inflammatory cells, our data indicate that CFs are important cells within the heart that produce IL- $1 \beta$. This finding is consistent with emerging evidence that $\mathrm{CFs}$ share many similarities with inflammatory cells in terms of how NLRP3 inflammasome/ IL- $1 \beta$ axis is activated and functions $[14,27,33]$. Although CFs comprise two-thirds of the cell population in the heart, they have not attracted much attention except in relation to processes related to myocardial fibrosis and remodeling. In recent years, however, several studies have demonstrated CFs could act as "sentinel" cells that sense danger signals and interact with other cells such as cardiomyocytes, vascular cells, and inflammatory cells in a paracrine manner [14,27]. Our observations provide strong support for the contention that CFs are the major cellular source of locally produced IL- $1 \beta$.

Herein, we provide evidence that the IL- $1 \beta$ secreted by CFs can impact on cardiomyocyte function. Since a quantitative assessment of myocyte contractile activity in our in vitro system was not possible, we used an indirect approach, i.e. assessment of intramyocyte cAMP levels. An increase in cAMP levels is associated with the increase in myocyte contractility induced by $\beta$-adrenergic agonists and has previously been used as an index of cardiomyocyte contractility. Impaired accumulation of cAMP in cardiomyocytes/myocardial tissue has been reported in in vitro and in vivo septic models $[12,40]$. In a similar vein, we show herein that IL-1 $\beta$ blunted the dobutamine-induced increase in intracellular cAMP in cardiomyocytes; an effect ameliorated by IL-1Ra. Cytokine-enriched supernatant from LPS-conditioned $\mathrm{CFs}$ also hampered cAMP accumulation in cardiomyocytes. Importantly, the role of CF NLRP3 inflammasome was highlighted because the decrease in cAMP production could be attenuated by pretreatment of the LPS-conditioned CFs with either NLRP3 siRNA or glyburide. However, it must be noted that the reversal afforded by inhibition of the NLRP3 inflammasome pathway was only partial. Thus, other, as yet unidentified, factors/agents generated by LPS (or IL-1 $\beta$ ) are likely to be involved in attenuating the dobutamine-induced increase myocyte cAMP.

In general, the basal level of NLRP3 is not sufficient for NLRP3 inflammasome activation [17]. Therefore, most of the previous studies probing the mechanisms involved in the activation of the NLRP3 inflammasome have employed two-step approaches: a priming step (LPS treatment) followed by an activation stimulus (ATP treatment in general) $[17,27,29]$. The priming approach using LPS increases the intracellular levels of NLRP3 and pro-IL$1 \beta$. The second activation step triggers both the formation of the inflammasome complex and the activation of caspase-1. 
A

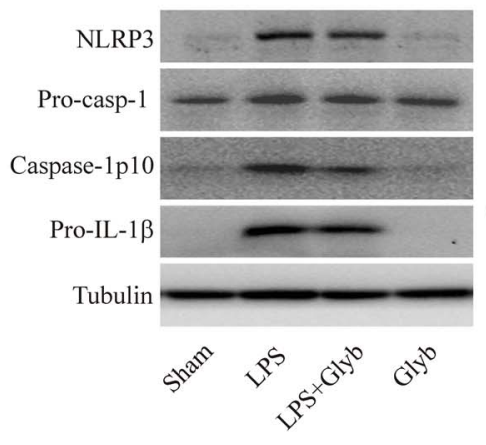

$\mathrm{B}$

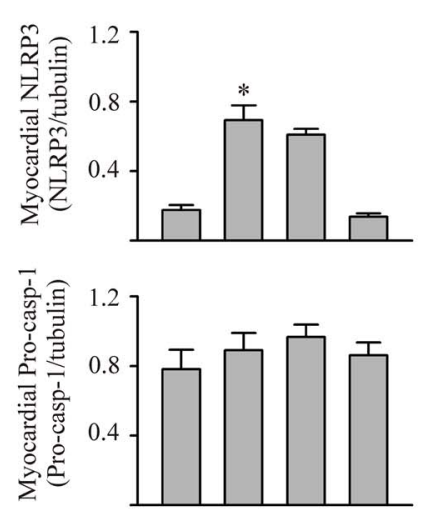

D

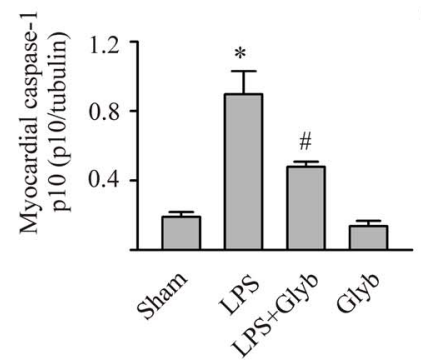

$\mathrm{E}$

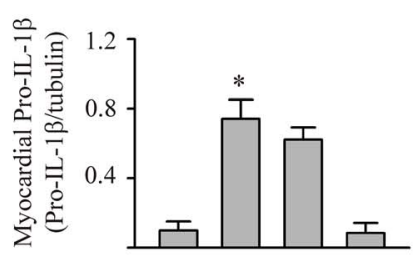

$\mathrm{F}$

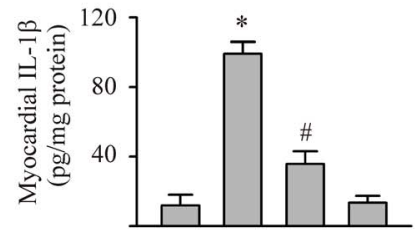

G

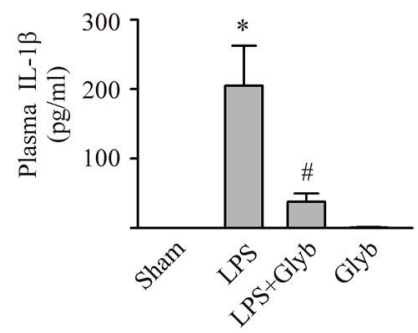

Figure 5. Inhibition of the NLRP3 inflammasome prevents LPS-induced increase in myocardial and circulating IL-1 $\beta$ in mice. Mice were injected (i.p.) with saline (sham), LPS $(10 \mathrm{mg} / \mathrm{kg})$, LPS with glyburide $(1 \mathrm{mg} / \mathrm{Kg})$, or glyburide alone. Eight hours later, myocardial tissue was harvested for measurement (Western blot) of NLRP3, pro-caspase-1, activated caspase-1p10, pro-IL-1 $\beta$ and IL-1 $\beta$. Representative Westerns shown in panel A and densitometric analyses in panels B-F. Mature (activated) II-1 $\beta$ in myocardial homogenates and plasma assessed with ELISA, panels F and $\mathrm{G}$, respectively. $\mathrm{n}=5$ for all experiments; ${ }^{*} \mathrm{p}<0.05$ compared with sham, $\# \mathrm{p}<0.05$ compared with LPS.

doi:10.1371/journal.pone.0107639.g005

Interestingly, in the present study, we demonstrated that a single LPS challenge itself is sufficient in activating the NLRP3 inflammasome/caspase-1/inflammasome pathway in CFs. The precise explanation for the discordant observations is not readily

A

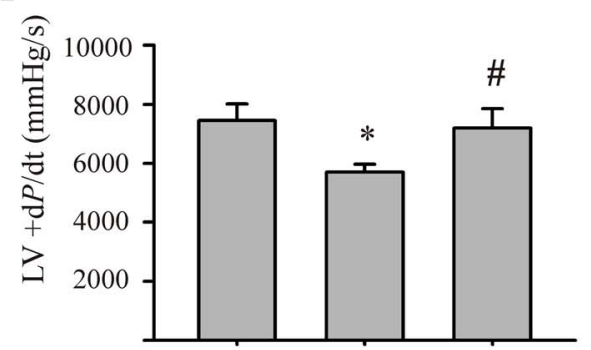

$\mathrm{B}$

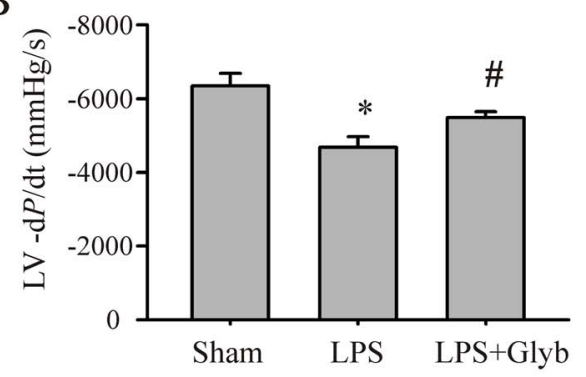

apparent. One potential explanation is that the treatment of the CFs in the present study resulted in the simultaneous increase in NLPR3 and its activation signals, such as ROS or DAMPs.
$\mathrm{C}$

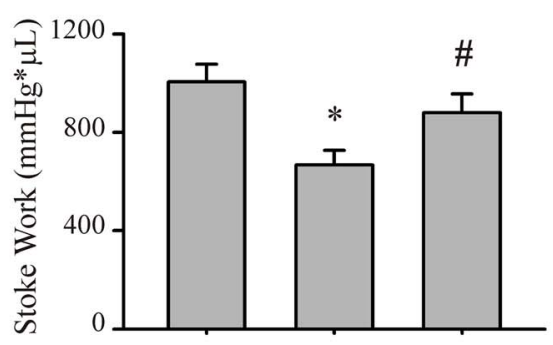

$\mathrm{D}$

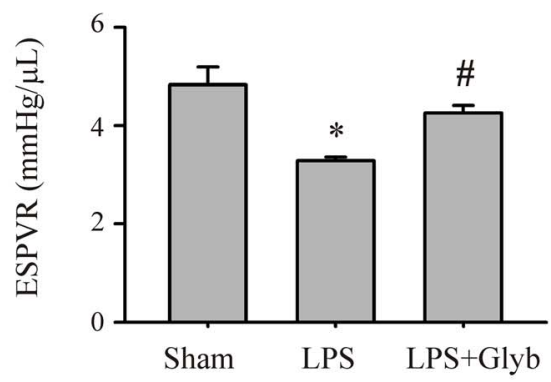

Figure 6. Inhibition of the NLRP3 inflammasome prevents myocardial contractile dysfunction in LPS-challenged mice. Mice were injected (i.p.) with saline (sham) or LPS (10 mg/Kg), or with LPS plus glyburide $(1 \mathrm{mg} / \mathrm{Kg})$. Myocardial contractile function (+dP/dt, $-\mathrm{dP} / \mathrm{dt}$, stroke work, and ESPVR) were assessed 24 hrs after LPS challenge with a mouse pressure-volume analysis system. $N=6$ for each group; ${ }^{*} \mathrm{p}<0.05$ compared with sham, $\# \mathrm{p}<0.05$ compared with LPS-challenged mice.

doi:10.1371/journal.pone.0107639.g006 


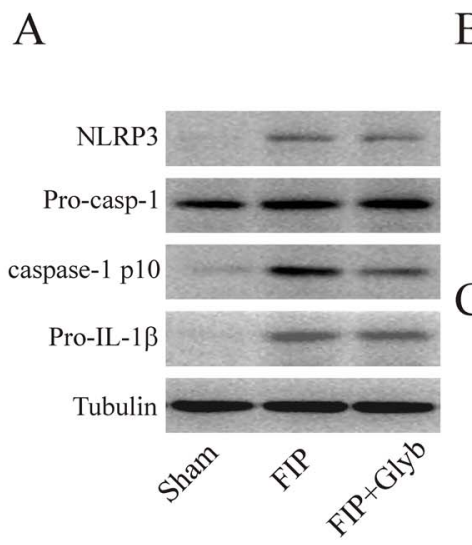

$\mathrm{B}$

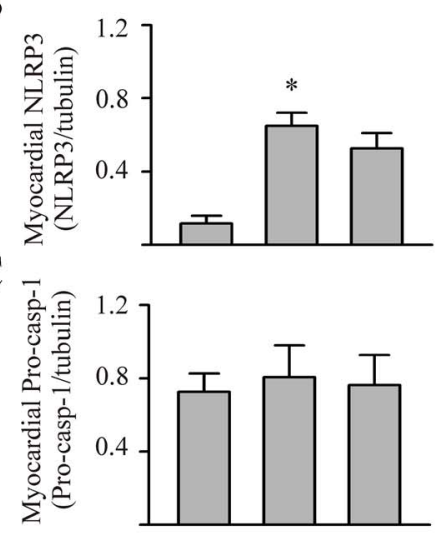

$\mathrm{D}$

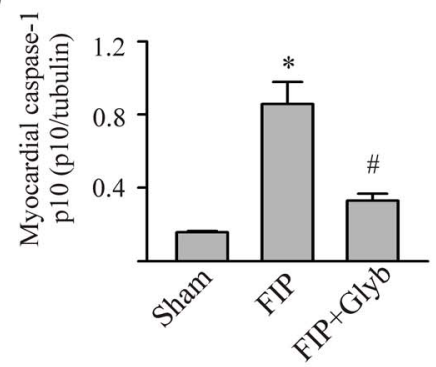

E

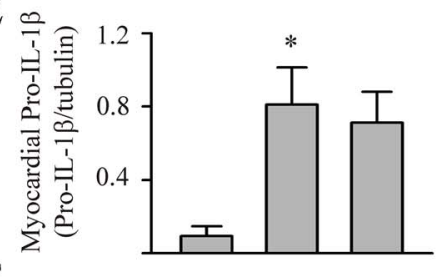

$\mathrm{F}$

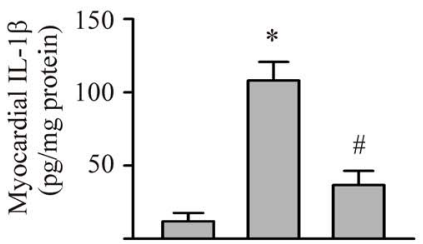

G

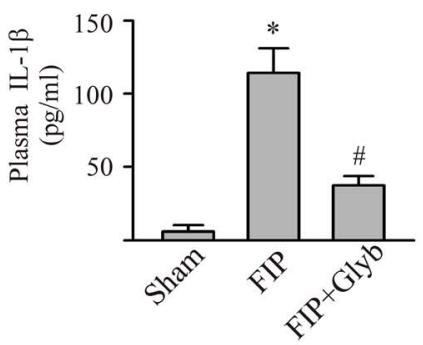

Figure 7. Sepsis-induced increases in myocardial and circulating IL-1 $\beta$ is reduced by inhibition of the NLRP3 inflammasome. Polymicrobial sepsis (FIP) was induced by i.p. injection of $0.5 \mathrm{ml}$ of fecal material $(30 \mathrm{mg} / \mathrm{ml})$. Myocardial tissue was harvested for measurement (Western blot) of NLRP3, pro-caspase-1, activated caspase-1 p10, and pro-IL-1 $\beta$. Representative Westerns are shown in panel A and densitometric analyses in panels B-E. Mature (activated) IL-1 $\beta$ in myocardial homogenates and plasma assessed with ELISA, panels $F$ and G, respectively. $n=5$ for all experiments; ${ }^{*} \mathrm{p}<0.05$ compared with sham, $\# \mathrm{p}<0.05$ compared with FIP. doi:10.1371/journal.pone.0107639.g007

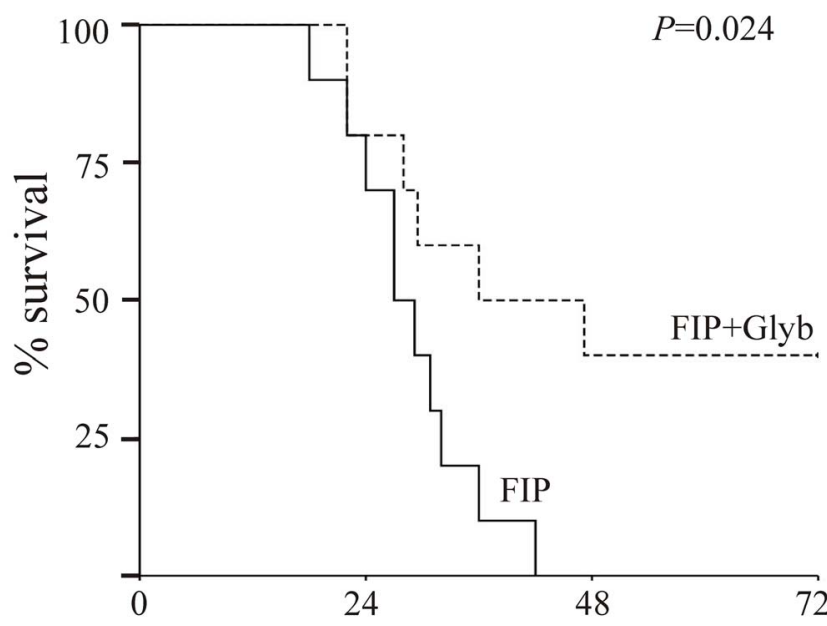

Hours after FIP

Figure 8. Sepsis-induced lethality is diminished by inhibition of the NLRP3 inflammasome. Polymicrobial sepsis (FIP) was induced by i.p. injection of $0.5 \mathrm{ml}$ of fecal material $(30 \mathrm{mg} / \mathrm{ml})$ in 20 mice; 10 of these mice also received glyburide ( $1 \mathrm{mg} / \mathrm{Kg}$, i.p. daily). The mice were monitored hourly for up to $72 \mathrm{hrs}$, and the survival rate was calculated. The survival rate of the two groups was compared with the KaplanMeier test, $p=0.024$.

doi:10.1371/journal.pone.0107639.g008
Although our findings strongly support a role for the NLRP3 inflammasome/caspase-1/ IL-1 $\beta$ pathway of CFs in the myocardial dysfunction, as well as, lethality in sepsis, extrapolation to the human condition is rather tenuous. Aside from the limitations of animal and cell models, i.e., humans are more sensitive to LPS than rodents [38], myocytes in culture may not represent the situation in situ [14], etc., a role for IL-1 $\beta$ in the clinical setting is unclear at present. Clinical trials using IL-1-based therapies have been disappointing with no clear or consistent benefit in sepsis demonstrated $[6,7]$. It has been suggested that grouping patients with heterogeneous conditions under the same diagnosis of "severe sepsis" contributed difficulty in reproduce results from pre-clinical experiments in clinical trials [28]. Further, the issue of synergy among various cytokines present in the "cytokine storm" of sepsis may cloud the issue. Cytokine synergy has been posited in sepsisinduced myocardial depression in previous studies [3,15]. The combination of IL- $1 \beta$ and TNF- $\alpha$ may cause cardiomyocyte depression at concentrations 50-100 times lower than would be required if applied individually [3,15]. In short, caution must be used in extrapolating data from pre-clinical experimental studies in cells and animals to the situation present in septic patients in the ICU. None the less, our observations suggest that the NLRP3 inflammasome may be a potential therapeutic target for the treatment of sepsis-induced myocardial dysfunction.

\section{Author Contributions}

Conceived and designed the experiments: WZ RK TM TR. Performed the experiments: WZ XX. Analyzed the data: WZ RK TM CMM TR. Contributed to the writing of the manuscript: RK TM PK CMM TR. 


\section{References}

1. Angus DG, Linde-Zwirble WT, Lidicker J, Clermont G, Carcillo J, et al. (2001) Epidemiology of severe sepsis in the United States: analysis of incidence, outcome, and associated costs of care. Crit Care Med 29: 1303-1310.

2. Boost KA, Hoegl S, Hofstetter C, Flondor M, Stegewerth K, et al. (2007) Targeting caspase-1 by inhalation-therapy: effects of Ac-YVAD-CHO on IL-1 beta, IL-18 and downstream proinflammatory parameters as detected in rat endotoxaemia. Intensive Care Med 33: 863-871.

3. Cain BS, Meldrum DR, Dinarello CA, Meng X, Joo KS, et al. (1999) Tumor necrosis factor-alpha and interleukin-1beta synergistically depress human myocardial function. Crit Care Med 27: 1309-1318.

4. Cohen J (2002) The immunopathogenesis of sepsis. Nature 420: 885-891.

5. Fallach R, Shainberg A, Avlas O, Fainblut M, Chepurko Y, et al. (2010) Cardiomyocyte Toll-like receptor 4 is involved in heart dysfunction following septic shock or myocardial ischemia. J Mol Cell Cardiol 48: 1236-1244.

6. Fisher CJ, Jr., Dhainaut JF, Opal SM, Pribble JP, Balk RA, et al. (1994) Recombinant human interleukin 1 receptor antagonist in the treatment of patients with sepsis syndrome. Results from a randomized, double-blind, placebo-controlled trial. Phase III rhIL-1ra Sepsis Syndrome Study Group. JAMA 271: 1836-1843

7. Fisher CJ Jr, Slotman GJ, Opal SM, Pribble JP, Bone RC, et al. (1994) Initial evaluation of human recombinant interleukin-1 receptor antagonist in the treatment of sepsis syndrome: a randomized, open-label, placebo-controlled multicenter trial. Crit Care Med 22: 12-21.

8. Gulick T, Chung MK, Pieper SJ, Lange LG, Schreiner GF (1989) Interleukin 1 and tumor necrosis factor inhibit cardiac myocyte beta-adrenergic responsiveness. Proc Natl Acad Sci U S A 86: 6753-6757.

9. Hernandez-Cuellar E, Tsuchiya K, Hara H, Fang R, Sakai S, et al. (2012) Cutting edge: nitric oxide inhibits the NLRP3 inflammasome. J Immunol 189: 5113-5117.

10. Hesse DG, Tracey KJ, Fong Y, Manogue KR, Palladino MA, et al. (1988) Cytokine appearance in human endotoxemia and primate bacteremia. Surg Gynecol Obstet 166: 147-153.

11. Ichinose F, Buys ES, Neilan TG, Furutani EM, Morgan JG, et al. (2007) Cardiomyocyte-specific overexpression of nitric oxide synthase 3 prevents myocardial dysfunction in murine models of septic shock. Circ Res 100: 130139.

12. Joe EK, Schussheim AE, Longrois D, Maki T, Kelly RA, et al. (1998) Regulation of cardiac myocyte contractile function by inducible nitric oxide synthase (iNOS): mechanisms of contractile depression by nitric oxide. J Mol Cell Cardiol 30: 303-315.

13. Kakkar R, Lee RT (2010) Intramyocardial fibroblast myocyte communication. Circ Res 106: 47-57.

14. Kawaguchi M, Takahashi M, Hata T, Kashima Y, Usui F, et al. (2011) Inflammasome activation of cardiac fibroblasts is essential for myocardial ischemia/reperfusion injury. Circulation 123: 594-604.

15. Kumar A, Thota V, Dee L, Olson J, Uretz E, et al. (1996) Tumor necrosis factor alpha and interleukin lbeta are responsible for in vitro myocardial cell depression induced by human septic shock serum. J Exp Med 183: 949-958.

16. Lamkanfi M, Mueller JL, Vitari AC, Misaghi S, Fedorova A, et al. (2009) Glyburide inhibits the Cryopyrin/Nalp3 inflammasome. J Cell Biol 187: 61-70.

17. Latz E, Xiao TS, Stutz A (2013) Activation and regulation of the inflammasomes. Nat Rev Immunol 13: 397-411.

18. Li P, Allen H, Banerjee S, Franklin S, Herzog L, et al. (1995) Mice deficient in IL-1 beta-converting enzyme are defective in production of mature IL-1 beta and resistant to endotoxic shock. Cell 80: 401-411.

19. Mariathasan S, Newton K, Monack DM, Vucic D, French DM, et al. (2004) Differential activation of the inflammasome by caspase- 1 adaptors ASC and Ipaf. Nature 430: 213-218.

20. Mariathasan S, Weiss DS, Newton K, McBride J, O'Rourke K, et al. (2006) Cryopyrin activates the inflammasome in response to toxins and ATP. Nature 440: 228-232.

21. Merx MW, Weber G (2007) Sepsis and the heart. Circulation 116: 793-802.

22. Rathinam VA, Vanaja SK, Fitzgerald KA (2012) Regulation of inflammasome signaling. Nat Immunol 13: 333-2.

23. Romero-Bermejo FJ, Ruiz-Bailen M, Gil-Cebrian J, Huertos-Ranchal MJ (2011) Sepsis-induced cardiomyopathy. Curr Cardiol Rev 7: 163-183.

24. Rossini A, Zacheo A, Mocini D, Totta P, Facchiano A, et al. (2008) HMGB1stimulated human primary cardiac fibroblasts exert a paracrine action on human and murine cardiac stem cells. J Mol Cell Cardiol 44: 683-693.
25. Rubartelli A (2012) Redox control of NLRP3 inflammasome activation in health and disease. J Leukoc Biol 92: 951-958.

26. Rui T, Feng Q Lei M, Peng T, Zhang J, et al. (2005) Erythropoietin prevents the acute myocardial inflammatory response induced by ischemia/reperfusion via induction of AP-1. Cardiovasc Res 65: 719-727.

27. Sandanger O, Ranheim T, Vinge LE, Bliksoen M, Alfsnes K, et al. (2013) The NLRP3 inflammasome is up-regulated in cardiac fibroblasts and mediates myocardial ischaemia-reperfusion injury. Cardiovasc Res 99: 164-174.

28. Scott AM, Saleh M (2007) The inflammatory caspases: guardians against infections and sepsis. Cell Death Differ 14: 23-31.

29. Sheedy FJ, Grebe A, Rayner KJ, Kalantari P, Ramkhelawon B, et al. (2013) CD36 coordinates NLRP3 inflammasome activation by facilitating intracellular nucleation of soluble ligands into particulate ligands in sterile inflammation. Nat Immunol 14: 812-820.

30. Singh VP, Baker KM, Kumar R (2008) Activation of the intracellular reninangiotensin system in cardiac fibroblasts by high glucose: role in extracellular matrix production. Am J Physiol Heart Circ Physiol 294: H1675-H1684.

31. Souders CA, Bowers SL, Baudino TA (2009) Cardiac fibroblast: the renaissance cell. Circ Res 105: 1164-1176.

32. Strutz F, Okada H, Lo CW, Danoff T, Carone RL, et al. (1995) Identification and characterization of a fibroblast marker: FSP1. J Cell Biol 130: 393-405.

33. Takahashi M (2013) NLRP3 in myocardial ischaemia-reperfusion injury: Inflammasome-dependent or -independent role in different cell types? Cardiovasc Res. 99: 4-5.

34. Thornberry NA, Bull HG, Calaycay JR, Chapman KT, Howard AD, et al. (1992) A novel heterodimeric cysteine protease is required for interleukin-1 beta processing in monocytes. Nature 356: 768-774.

35. Tokudome T, Horio T, Yoshihara F, Suga S, Kawano Y, et al. (2004) Direct effects of high glucose and insulin on protein synthesis in cultured cardiac myocytes and DNA and collagen synthesis in cardiac fibroblasts. Metabolism 53: $710-715$.

36. Tschopp J, Schroder K (2010) NLRP3 inflammasome activation: The convergence of multiple signalling pathways on ROS production? Nat Rev Immunol 10: 210-215

37. Weisensee D, Bereiter-Hahn J, Schoeppe W, Low-Friedrich I (1993) Effects of cytokines on the contractility of cultured cardiac myocytes. Int J Immunopharmacol 15: 581-587.

38. Wichterman KA, Baue AE, Chaudry IH (1980) Sepsis and septic shock-a review of laboratory models and a proposal. J Surg Res 29: 189-201.

39. Wiersinga WJ (2011) Current insights in sepsis: from pathogenesis to new treatment targets. Curr Opin Crit Care 17: 480-486.

40. Wu LL, Tang C, Dong LW, Liu MS (2002) Altered phospholamban-calcium ATPase interaction in cardiac sarcoplasmic reticulum during the progression of sepsis. Shock 17: 389-393.

41. Xu H, Su Z, Wu J, Yang M, Penninger JM, et al. (2010) The alarmin cytokine, high mobility group box 1 , is produced by viable cardiomyocytes and mediates the lipopolysaccharide-induced myocardial dysfunction via a TLR4/phosphatidylinositol 3-kinase gamma pathway. J Immunol 184: 1492-1498.

42. Xu H, Yao Y, Su Z, Yang Y, Kao R, et al. (2011) Endogenous HMGB1 contributes to ischemia/reperfusion-induced myocardial apoptosis by potentiating the effect of TNF\{alpha\}/JNK. Am J Physiol Heart Circ Physiol 300: H913-H921.

43. Yang M, Wu J, Martin CM, Kvietys PR, Rui T (2008) Important role of p38 MAP kinase/NF- $\{$ kappa $\} \mathrm{B}$ signaling pathway in the sepsis-induced conversion of cardiac myocytes to a proinflammatory phenotype. Am J Physiol Heart Circ Physiol 294: H994-H1001.

44. Yao Y, Xu X, Zhang G, Zhang Y, Qian W, et al. (2012) Role of HMGB1 in doxorubicin-induced myocardial apoptosis and its regulation pathway. Basic Res Cardiol 107: 267.

45. Yazdi AS, Drexler SK, Tschopp J (2010) The role of the inflammasome in nonmyeloid cells. J Clin Immunol 30: 623-627.

46. Zhang P, Su J, Mende U (2012) Cross talk between cardiac myocytes and fibroblasts: from multiscale investigative approaches to mechanisms and functional consequences. Am J Physiol Heart Circ Physiol 303: H1385-H1396.

47. Zhang Z, Xu X, Ma J, Wu J, Wang Y, et al. (2013) Gene deletion of Gabarap enhances Nlrp3 inflammasome-dependent inflammatory responses. J Immunol 190: $3517-3524$ 